\title{
Quantitative, Real-Time Measurements of Intracellular Target Engagement Using Energy Transfer
}

\author{
Matthew B. Robers, James D. Vasta, Cesear R. Corona, \\ Rachel Friedman Ohana, Robin Hurst, Manisha A. Jhala, \\ Kenneth M. Comess, and Keith V. Wood
}

\begin{abstract}
Intracellular target affinity and residence time are fundamental aspects of pharmacological mechanism ( $\mathrm{Lu}$ and Tonge, Curr Opin Chem Biol 14:467-474, 2010). Although various robust biochemical approaches exist to measure these binding characteristics, analysis of compound binding with isolated targets may not accurately reflect engagement in the milieu of living cells. To realize the influence of cellular context, methods are needed that are capable of quantifying affinity and residence time in the presence of the intracellular factors that may impact target engagement. Bioluminescence resonance energy transfer (BRET) offers a solution for intracellular target engagement when quantitative metrics or kinetic analyses are required.
\end{abstract}

Key words Target engagement, Residence time, Intracellular affinity, NanoBRET(TM), BRET

1 Introduction

While quantitation of compound binding to isolated targets is readily achieved, similar biophysical assessments in living systems represent a challenge. Cell-based assays of target engagement are most commonly achieved by assessing the dynamics of cell signaling. Although these methods allow for interrogation of compound potency using live cells, pathway analysis methods generally integrate the activities of multiple protein targets. Consequently, the molecular targets of drug molecules can be ambiguous when analyzed within the framework of a pathway. The ideal target engagement format provides a direct, biophysical assessment of compound binding at the selected intracellular target, therefore providing a bridge between reductionist biochemical assays and traditional cellular pathway analysis readouts. 
A number of novel techniques have been recently developed that allow for the interrogation of targets derived from cells or cell extracts. Each technique offers certain advantages and disadvantages that should be evaluated according to the requirements of the study. The cellular thermal shift assay (CETSA) represents a significant advancement for cellular analysis, as it queries compound binding of endogenously expressed targets, using intact cells [1]. However, CETSA is an indirect measure of compound engagement, and is reportedly prone to noteworthy false negative and false positive results for clinically relevant probe molecules [1]. Activitybased proteomics reagents offer a more direct assessment of compound binding via mass spectrometry (MS) [2]. However, the majority of such MS techniques involve dissolution of the cell membrane, and consequently a dilution of key cellular factors that are known to impact inhibitor potency. While these methods enable analysis of endogenously expressed targets, each has a significant limitation that should be considered. Activity-based proteomics methods do not assess target engagement under a thermodynamic equilibrium with the unlabeled drug molecule in living cells, thus limiting their ability to measure intracellular affinity. Acquisition of CETSA data to estimate $\mathrm{IC}_{50}$ values can be labor-intensive and does not necessarily correlate directly to thermodynamic affinity. Such approaches also fail to offer real-time analysis of target engagement inside intact cells. When quantitation of affinity and residence time is desired, alternate approaches should be considered.

A recently described technique using Bioluminescence Resonance Energy Transfer (BRET) offers a quantitative analysis of target engagement in living cells under both equilibrium and nonequilibrium conditions $[3,4]$. This method, termed NanoBRET $(\mathrm{TM})$, is a highly sensitive measure of molecular proximity and offers a direct and real-time capability for measuring molecular interactions in live cells. Briefly, reporter complexes are formed inside live cells, when a luciferase (e.g., $\operatorname{NanoLuc}(\mathrm{R})$ ) -tagged target protein reaches dynamic equilibrium with cell-permeable fluorescent probe molecules (tracers). Upon binding of an unlabeled compound, the complex is disrupted, leading to a loss of BRET that can easily be monitored and scaled in a microplate format (Fig. 1). In many cases, the NanoBRET tracers can be readily designed from drug or tool compounds, generally offering a quantitative analysis of apparent affinity and a real-time analysis of residence time $[3,5-7]$.

However, this approach has technical requirements that must first be considered and carefully followed in order to achieve quantitation in live cells. The following chapter outlines: (1) considerations for development of novel cell-permeable tracers, (2) optimization of conditions for intracellular BRET, and (3) protocols for quantitative and real-time analysis of target engagement in live cells in the context of HTS work flows. 


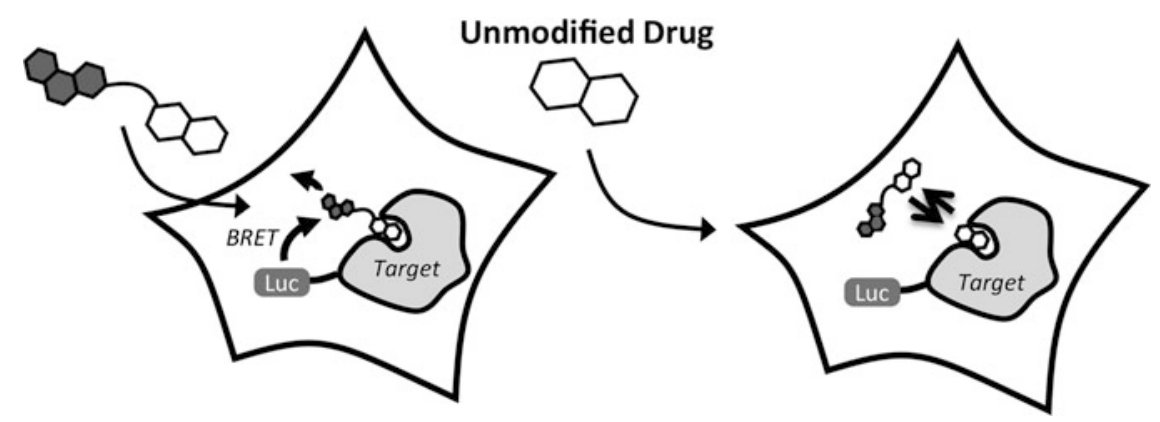

Fig. 1 Illustration of target engagement via energy transfer

\section{Materials}

2.1 Development and Characterization of NanoBRET ${ }^{\text {TM }}$ Tracers with Optimal Cell Permeability
2.2 Verification of Tracer Permeability and Optimization of BRET
1. Functionalized small molecule precursor with a primary amine group.

2. $5 \mathrm{~mL}$ amber vials.

3. $30 \mathrm{~mL}$ plastic bottle.

4. Anhydrous dimethylformamide (DMF).

5. N,N-Diisopropylethylamine.

6. NanoBRET ${ }^{\mathrm{TM}} 590 \mathrm{SE}$ and NanoBRET ${ }^{\mathrm{TM}}$ 618-TFP.

7. Analytical HPLC.

8. Reaction quenching solution: $1: 1: 0.01(\mathrm{v} / \mathrm{v} / \mathrm{v})$ water-acetonitrile-trifluoroacetic acid (TFA).Combine $5 \mathrm{~mL}$ water and $5 \mathrm{~mL}$ acetonitrile in a $30 \mathrm{~mL}$ plastic bottle and add $0.1 \mathrm{~mL}$ trifluoroacetic acid (TFA).

9. Trifluoroacetic acid (TFA) HPLC Buffer: 0.1\% TFA in water. Add $4 \mathrm{~mL}$ TFA to a $4 \mathrm{~L}$ bottle of HPLC grade water and mix.

1. Desired cell type (e.g., HEK293).

2. White, nonbinding surface (NBS) 96-well plates, appropriately coated to avoid adsorptive properties of the fluorescent tracers.

3. NanoBRET Tracer Dilution Buffer (Promega).

4. Polypropylene plastic ware (buffer troughs, serial dilution troughs, etc.).

5. Miscellaneous tissue culture reagents and plasticware, including, standard cell culture growth medium.

6. Assay medium: Opti-MEM without phenol red (Gibco).

7. Transfection reagent.

8. Promoterless DNA (Transfection Carrier DNA, Promega).

9. Extracellular NanoLuc(R) Inhibitor (Promega). 


\subsection{Considerations for Quantitation of Compound Affinity by Competitive Displacement of Tracers}

\subsection{Liquid Handling Requirements and Considerations for High-Throughput Screening and Lead Optimization}

2.5 Optimization of Energy Transfer for Residence Time Studies in Live Cells
10. Luciferase substrate (NanoBRET(TM) Nano-Glo(R) Substrate, Promega).

11. Dimethylsulfoxide (DMSO).

12. Tracer: 100-400 $\mu \mathrm{M}$ in DMSO (stored at $-80{ }^{\circ} \mathrm{C}$; avoid freeze/thaw cycles).

13. Plasmid DNA encoding $\operatorname{NanoLuc}(\mathrm{R})$ fusion under control of a mammalian promoter (e.g., in a $\mathrm{pFN} 31 \mathrm{~K}$ or $\mathrm{pFN} 32 \mathrm{~K}$ vector, Promega).

14. $250 \mu \mathrm{g} / \mathrm{mL}$ digitonin in water (or $50 \mathrm{mg} / \mathrm{mL}$ digitonin in DMSO).

15. 5× Passive Lysis Buffer (Promega).

16. A BRET-compatible luminometer equipped with $450 \mathrm{~nm}$ (bandpass) and $600 \mathrm{~nm}$ (longpass) filters. (e.g., Glomax Discover, PerkinElmer EnVision, or BMG Clariostar).

1. Same reagents as described in Subheading 2.2.

1. Same reagents as described in Subheading 2.2.

2. Acoustic liquid handling technology capable of nanoliter dispensing of test and control compounds in DMSO solvent, e.g., Labcyte Echo 550 Liquid Handler.

3. Electronic 16-channel repeat pipettors, e.g., Thermo Fisher E1-ClipTip ${ }^{\text {TM }} 384$ Multichannel Electronic Pipette and tips.

4. Agilent PlateLoc Thermal Microplate Sealer and Agilent peelable aluminum seals.

5. White, 384-well nonbinding surface (NBS) plates (Corning).

1. Same reagents described in Subheading 2.2.

2. Assay plates: white, opaque, tissue cultured-treated (TC) 96-well plates.

3. Vacuum aspirator with eight-channel adapter.

4. A BRET-compatible luminometer, equipped as described earlier (see Subheading 2.2), and with repeat read capabilities over at least $2 \mathrm{~h}$ intervals. 


\section{Methods}

3.1 Development and Characterization of NanoBRET TM Tracers with Optimal Cell Permeability
To achieve quantitation in living cells, the BRET technique exploits permeable fluorescent reporter probes (or tracers), derived from chemical matter with appropriate binding characteristics for the select target protein or protein family. Tracers may be derived from compounds with high selectivity for the target protein, but in many cases, broad-spectrum inhibitors or published tool compounds can be utilized to achieve greater coverage if desired [4].

The chemical synthesis of functional tracers involves the covalent conjugation of a biologically active small molecule to a fluorescent organic dye. Certain organic dyes have proven optimal in maintaining cell permeability with spectral properties required for NanoBRET(TM) (Fig. 2a). These dyes are readily coupled to base compounds containing pendant amine groups via a one-step reaction of a highly reactive, activated ester group on the dye to produce a stable amide linkage.

Tracers must permeate live cells and function in a complex intracellular environment. Thus, there are several physical requirements that must be considered during the design phase. First, high affinity compounds may yield the most useful intracellular tracers. Within the milieu of cells, strong affinity may be required to overcome competition from endogenous metabolites or enzymatic
A

\section{NanoBRET 590 SE}<smiles></smiles>

B

\section{PEGylated-amino linkers}<smiles>CC(C)(C)OCCNCCOCCBr</smiles><smiles>CC(C)(C)OC(=O)NCCOCCOCCOCCOCCC(=O)O</smiles><smiles></smiles>

Alkyl-amino linkers<smiles>CC(C)(C)OC(=O)NCCCC(=O)O</smiles><smiles>CC(C)(C)OCCNCCCCCC(=O)O</smiles>

Fig. 2 The structures of NanoBRET(TM) activated ester dyes (a) and example linker building blocks (b). NanoBRET(TM) dyes balance permeability and energy transfer efficiency, resulting in higher signal, stability and reactivity. Dyes directly coupled to the inhibitor yield the tracers, though it may be necessary to install a linker group to provide separation between the core and the fluorescent tag. In general, C3 to C6 alkyl, as well as 01 to 04 PEGs are suitable as starting points 
3.1.1 Example Synthesis of Amine-Linked Tracers substrates that may compete directly with the tracer. Second, the intrinsic binding kinetics of tracer for the target may also be important for consideration. In general, compounds with rapid equilibration kinetics also offer better capabilities for real-time analysis of target engagement (i.e., residence time analysis). Finally, the base scaffold must have a solvent exposed reactive group for conjugation. This site can be determined through cocrystal structure, SAR analysis, or homology models. Although a variety of synthetic approaches can be employed, NanoBRET(TM) dyes prepared as activated esters can be readily conjugated to the scaffold via a primary or secondary aliphatic amine. These amine groups have been shown to react quickly and quantitatively with activated ester dyes and amino acid linkers.

A variety of dye classes have been evaluated in BRET assay formats, and dyes representing two fluorophore classes (Fig. 2a) have been identified that demonstrate consistently robust cell permeability and optimal spectral overlap for energy transfer. Derivatives containing varied linkers and dyes may perform differently in the assay (examples provided in Fig. 2). Therefore, as a starting point for assay development, it is initially recommended that at least four derivatives be prepared and evaluated in the BRET configuration: Minimal/no linker derivatives conjugated to NanoBRET ${ }^{\mathrm{TM}}$ 618 and NanoBRETTM 590 dyes and extended linkers (e.g., multiPEG or alkyl derivatives) conjugated to NanoBRET ${ }^{\text {тм }} 618$ and NanoBRET ${ }^{\text {TM }} 590$ dyes. This panel of tracer candidates can be created from common intermediates and will provide structural diversity required to ensure the highest probability of success, and if required, guide further optimization. To serve as examples, these principles have been employed to create a panel of candidate cellpermeable tracers based on crizotinib, a multikinase inhibitor scaffold (Fig. 3).

1. Charge the small molecule precursor, functionalized with an amine, $(9.9 \mu \mathrm{mol})$ into a $5 \mathrm{~mL}$ amber vial.

2. Add $0.5 \mathrm{~mL}$ anhydrous dimethylformamide (DMF) and stir.

3. Add $8.6 \mu \mathrm{L} N, N$-Diisopropylethylamine, allowing the mixture to stir for $10 \mathrm{~min}$.

4. Add $5.0 \mathrm{mg}$ NanoBRETTM 590 SE. Cap and allow to react in the dark for $1 \mathrm{~h}$.

5. Monitor the reaction for consumption of the starting amine by analytical HPLC. The reaction is judged complete when this material has been consumed. The reaction progresses quickly and is often near completion after $30 \mathrm{~min}$ ( see Note $\mathbf{1}$ ).

6. Dilute the crude mixture with the reaction quenching solution.

7. Purify the compound using reverse-phase preparative HPLC. Most tracers can be purified using standard HPLC methods. 


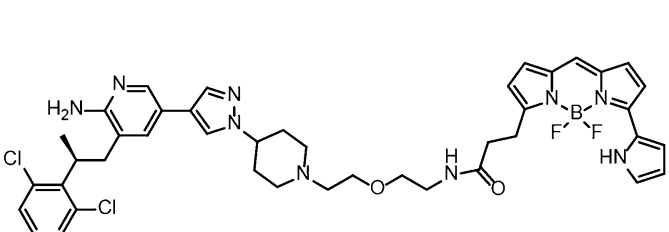

Crizotinib-mono-PEG-NB590

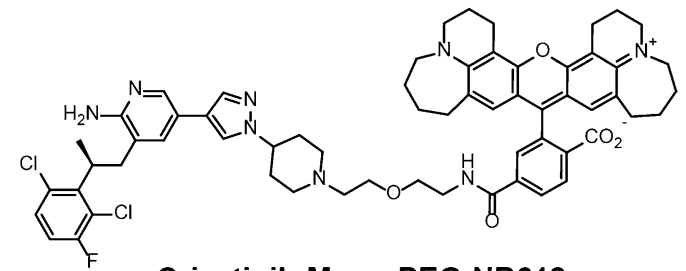

Crizotinib-Mono-PEG-NB618<smiles></smiles>

\section{Crizotinib-Tetra-PEG-NB590}
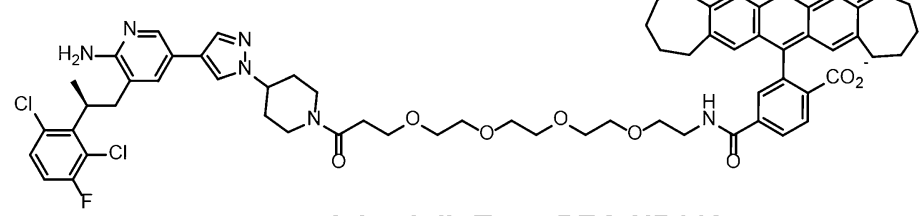

Crizotinib-Tetra-PEG-NB618

Fig. 3 Chemical structures of four candidate tracer derivatives based upon the crizotinib scaffold. Similar dye/linker variants can be created for a wide variety of base molecules by conjugation to solvent exposed primary or secondary amines

\subsection{Verification of Tracer Permeability and Optimization of BRET}

Use a gradient of trifluoroacetic acid (TFA) HPLC Buffer (or $0.1 \%$ formic acid in water) in acetonitrile as an eluent.

8. Pool product containing fractions and concentrate to dryness under reduced pressure.

9. Dissolve the resulting film in approximately $10 \mathrm{~mL}$ acetonitrile and concentrate to dryness a total of three times (see Note 2).

10. Dry the resulting film for a minimum of $1 \mathrm{~h}$ to remove trace volatile solvents.

11. Dissolve the resulting solid in an appropriate volume of DMSO to give a $2.0 \mathrm{mM}$ solution.

12. Calculate the concentration of the solution using the following molar extinction coefficients: $\varepsilon_{\text {NanoBRET }}{ }^{\text {тм }} 590=$ $83,000 \mathrm{M}^{-1} \mathrm{~cm}^{-1}, \varepsilon_{\text {NanoBRET }}{ }^{\mathrm{Tm}} 618=96,000 \mathrm{M}^{-1} \mathrm{~cm}^{-1}$.

BRET is highly sensitive to molecular distance and orientation between the donor (luciferase) and acceptor (fluorescent tracer) partners. This feature enables a bona fide measurement of direct molecular interactions inside intact cells. However, optimization may be warranted to identify the conditions producing optimal BRET between the donor/acceptor partners. This can generally 


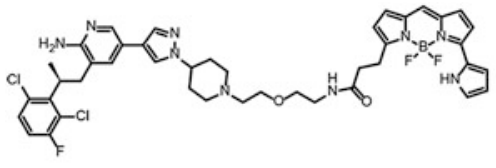

MET

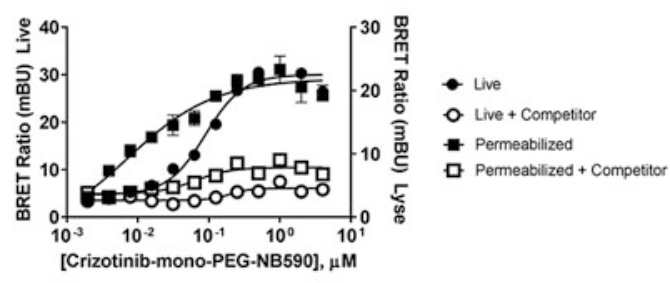

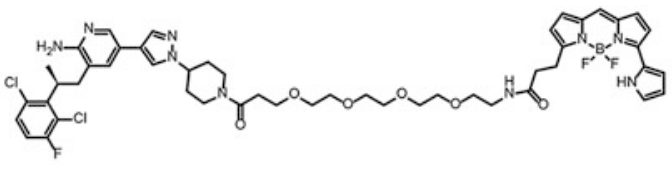

MET

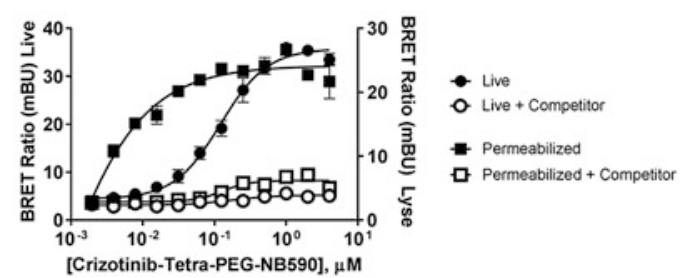

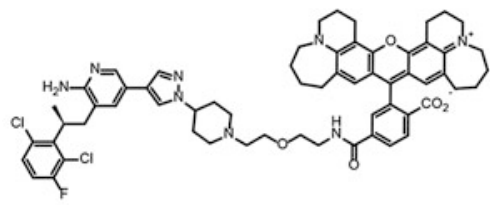

MET

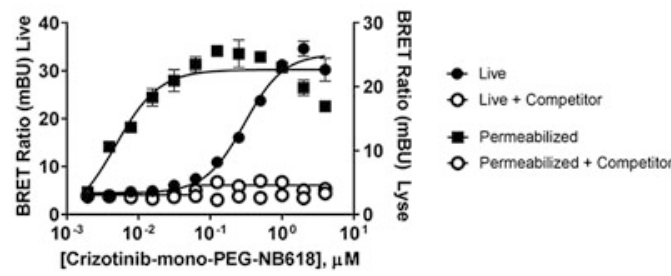

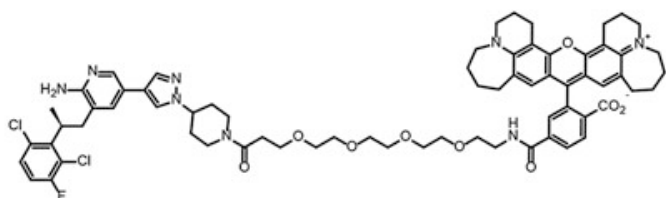

MET

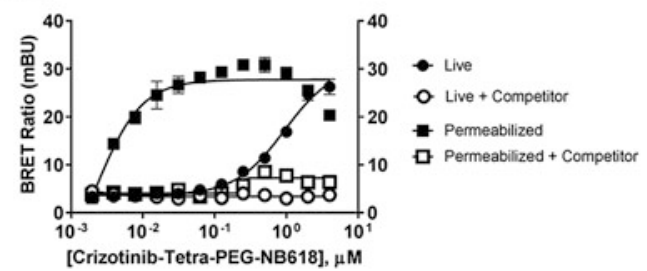

Fig. 4 Verification of tracer permeability and affinity. HEK293 cells transfected with NanoLuc(R) fusion plasmids were titrated with tracers. Cells treated with $50 \mu \mathrm{g} / \mathrm{mL}$ digitonin were included as controls for engagement of poorly permeable tracers. Each tracer demonstrated specific BRET with MET kinase in live cells and permeabilized cells. Both of the NanoBRET(TM) 590 tracers yielded the strongest cellular engagement and proved to be optimal for MET kinase. In certain cases, alternate dye/linker combinations may prove optimal

be achieved without a laborious effort, via transient transfection of plasmids encoding target/NanoLuc(R) fusion proteins (see Note 3) [4]. The following basic protocol can be used to determine the optimal orientation of $\operatorname{NanoLuc}(R)$ luciferase for target engagement analysis via BRET. It is generally recommended that novel NanoBRET(TM) tracers are evaluated in both live cells, as well as permeabilized cells (via addition of digitonin or Passive Lysis buffer), to assess tracer affinity in the absence of interfering cellular factors. Figure 4 provides an example where the protocol is used to determine the optimal tracer for a kinase target, and Figs. 5 and 6 provide examples wherein the protocol is used to determine optimal $\operatorname{NanoLuc}(\mathrm{R})$ fusion orientation or expression level, respectively. 

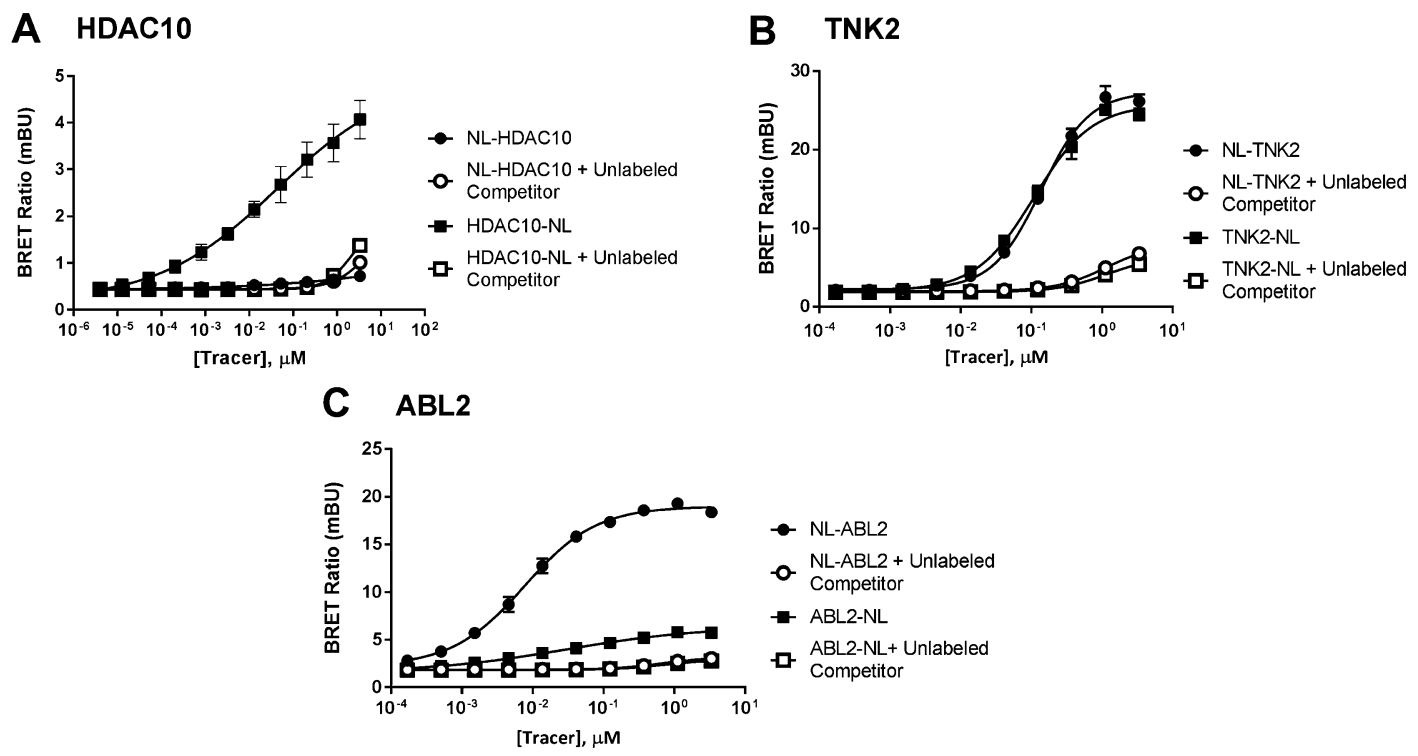

Fig. 5 Optimization of NanoLuc(R) orientation for BRET. (a) For HDAC10, BRET was optimal with NanoLuc(R) on the $\mathrm{C}$-terminus of the target protein. For (b) TNK2 both $\mathrm{N}$ - and $\mathrm{C}$-terminal NanoLuc(R) fusions performed optimally in BRET experiments. (c) For ABL2, both $\mathrm{N}$ - and $\mathrm{C}$-terminal NanoLuc(R) fusions performed in BRET experiments, but the $\mathrm{N}$-terminal placement of NanoLuc(R) performed optimally. $\mathrm{N}$ - and $\mathrm{C}$-terminal orientations should be tested when possible

\section{A H1 Receptor}

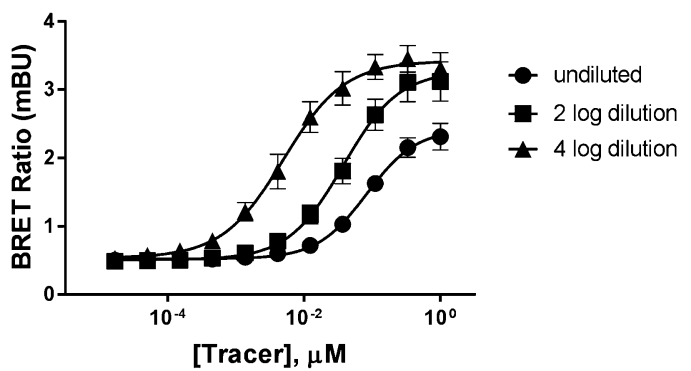

B DDR1

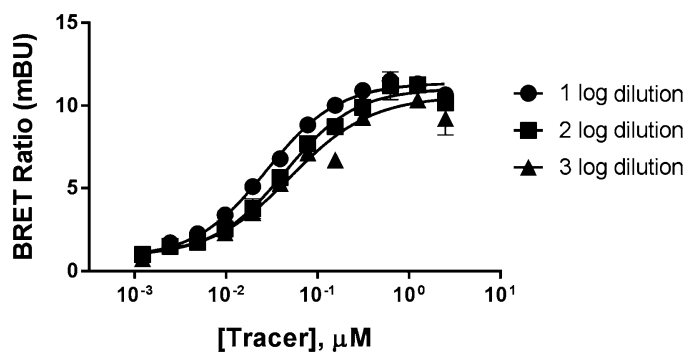

Fig. 6 Optimization of expression levels for BRET studies. Expression levels can be easily optimized by dilution of the expression plasmids into a promoterless carrier DNA (Transfection Carrier DNA). This maintains a constant amount of DNA for transfection, but allows for lower expression levels across the population of transfected cells. (a) For the GPCR example (Histamine H1 receptor), BRET signal and tracer engagement was sensitive to expression levels, supporting use of lower expression levels for the receptor of interest. (b) For DDR1 kinase, BRET and tracer engagement was unaffected by expression levels. In general, it is recommended that low expression levels be used to ensure physiological conditions and avoid ligand depletion

3.2.1 [Day 1]: Transient Transfection of HEK293 Cells with $\operatorname{NanoLuc}(R)$ Fusions
1. Cultivate desired cells (e.g., HEK293) appropriately prior to assay and resuspend cells into a single-cell suspension using complete cell culture medium.

2. Adjust the cell density to $2 \times 10^{5} / \mathrm{mL}$ in cell culture medium in a sterile, conical tube. 
3.2.2 [Day 2]:

Preparation of Cells with $1 \times$ Tracer for BRET Assay
3. Prepare plasmid DNAs for transfection. For first-time experiments, use a 1:10 dilution (mass:mass) of expression construct into a promoterless DNA (Transfection Carrier DNA). At this stage it may be useful to perform a titration of expression, by diluting the expression construct into Transfection Carrier DNA. Examples of extending this titration are shown in Fig. 6.

4. Prepare transfection complexes using the manufacturer's protocol.

5. Mix one part (e.g., $1 \mathrm{~mL}$ ) of transfection complex with 20 parts (e.g., $20 \mathrm{~mL}$ ) of HEK 293 cells in suspension at $2 \times 10^{5} / \mathrm{mL}$. Mix gently by inversion five times in a sterile, conical tube.

6. Dispense cells/lipid-DNA complex into a sterile tissue culture flask, and incubate at least $20 \mathrm{~h}$ to allow expression to occur. We recommend a cell density of approximately 55,000-80,000 cells $/ \mathrm{cm}^{2}$ during the transfection (for example use approximately 4-6 million cells for a T75 flask). Larger or smaller bulk transfection should be scaled accordingly, using this ratio.

1. Harvest cells via trypsinization, and resuspend in growth medium including serum. Centrifuge the cells and resuspend the pellet in Opti-MEM without serum or phenol red.

2. Adjust the cell density to $2 \times 10^{5} / \mathrm{mL}$ in Opti-MEM without serum or phenol red.

3. Prepare cells for target engagement analysis in live or permeabilized cells. For live cell target engagement experiments, dispense $85 \mu \mathrm{L}$ per well of cell suspension into white, 96-well NBS plate. Periodically mix cells appropriately to avoid settling of the cell suspension. For live cell analysis, proceed to step 4. For permeabilized cell experiments dispense $68 \mu \mathrm{L}$ cell suspension per well into a white, 96-well plate. Add $17 \mu \mathrm{L}$ of lysis reagent (either $5 \times$ Passive Lysis Buffer or $250 \mu \mathrm{g} / \mathrm{mL}$ digitonin).

4. Prepare the complete $20 \times$ tracer. For characterization of tracer affinity, perform a serial dilution of the tracer in DMSO at a $100 \times$ concentration ( see Note 4 ). For characterization of unlabeled drug affinity (if the optimal concentration of tracer has already been determined) prepare a $100 \times$ concentration of the tracer in pure DMSO.

5. Dilute the $100 \times$ tracers to $20 \times$ with Tracer Dilution Buffer according to the manufacturer's instructions. Add 4 parts Tracer Dilution Buffer to 1 part of $100 \times$ tracer (from DMSO) to prepare the Complete $20 \times$ tracer reagent.

6. Mix gently several times to ensure that the DMSO solution is mixed with the tracer dilution buffer.

7. Add $5 \mu \mathrm{L}$ of complete $20 \times$ tracer reagent per well to cells in suspension. 
3.2.3 [Day 2]: Addition of Test Compounds for Competition Analysis and Determination of Specific BRET
3.2.4 Detection in Microplate Luminometer Equipped with Appropriate BRET Filters
8. Mix on orbital shaker for $15 \mathrm{~s}$ at $900 \mathrm{rpm}$. Mixing may vary between orbital shakers and should be optimized for each individual unit accordingly. Due to the viscosity of the Tracer Dilution Buffer, it is necessary to dispense this solution slowly.

1. Prepare a suitable unlabeled test compound at $1000 \times$ final concentration in $100 \%$ DMSO. Typically, the $1000 \times$ concentration of compound is in the $10-100 \mathrm{mM}$ range. Then dilute to a $10 \times$ final concentration in Opti-MEM without serum or phenol red.

2. The characterization of BRET tracers can be performed as a single concentration of unlabeled compound for tracer dose-response curves. It is generally recommended that a $20-100 \times$ molar excess of parental drug is coincubated with the tracer to determine the nonspecific BRET signal.

3. For characterization of unlabeled drug $\mathrm{IC}_{50}$, create a serial dilution of test compound for drug $\mathrm{IC}_{50}$ analysis.

4. Add $10 \mu \mathrm{L}$ per well of $10 \times$ inhibitor/test compound to the 96-well plates containing cells with $1 \times$ tracer. Mix on orbital shaker for $15 \mathrm{~s}$ at $900 \mathrm{rpm}$.

5. Incubate the plate at $37{ }^{\circ} \mathrm{C}$ and $5 \% \mathrm{CO}_{2}$ for $2 \mathrm{~h}$. Allow plate to cool to room temperature for approximately $15 \mathrm{~min}$, then proceed to the next section below.

6 . For permeabilized cell assays, incubate the plate at room temperature, protected from light for $1-2 \mathrm{~h}$ (depending on the characteristics of the test compound). Then proceed with the next step (see Subheading 3.2.4).

1. Immediately prior to BRET measurements, prepare $3 \times$ Complete NanoBRET(TM) Nano-Glo(R) Substrate.

2. For live cell analysis, add Extracellular NanoLuc(R) Inhibitor in Opti-MEM and add to cells according to the manufacturer's instructions (Promega) (see Note 5).

3. For Permeabilized cell analysis, prepare $3 \times$ NanoBRET(TM) Nano-Glo(R) Substrate in Opti-MEM without serum or phenol red, and omit the Extracellular $\operatorname{NanoLuc}(\mathrm{R})$ Inhibitor. This solution consists of only a 1:166 dilution of NanoBRET(TM) Nano-Glo(R) Substrate in Opti-MEM.

4. Following addition of $50 \mu \mathrm{L}$ of NanoBRET(TM) Nano-Glo(R) Substrate, measure donor emission (e.g., $450 \mathrm{~nm}$ ) and acceptor emission (e.g., $610 \mathrm{~nm}$ or $630 \mathrm{~nm}$ ) using a NanoBRET(TM)compatible luminometer.

5. To generate raw BRET ratio values, divide the acceptor emission value (e.g., $610 \mathrm{~nm}$ ) by the donor emission value (e.g., $450 \mathrm{~nm}$ ) for each sample. Convert raw BRET units to 


\subsection{Considerations for Quantitation of Compound Affinity by Competitive Displacement of Tracers}

milliBRET units ( $\mathrm{mBU}$ ) by multiplying each raw BRET value by 1000 .

6. (Optional) If a background correction is desired, use the NanoBRET Equation (Eq. 1).

$$
\left(\frac{\text { Acceptor }_{\text {sample }}}{\text { Donor }_{\text {sample }}}-\frac{\text { Acceptor }_{\text {no tracer control }}}{\text { Donor }_{\text {no tracer control }}}\right) \times 1000
$$

As described above (see Subheading 3.2), the basic protocol details the measurement of the intracellular engagement potency $\left(\mathrm{IC}_{50}\right.$ of BRET attenuation) of a test compound at a single concentration of tracer. In general, compound affinity is measured under steadystate conditions between the test compound, the tracer, and the intracellular target protein. For the simple determination of compound rank-order affinity, it is recommended to use the tracer at a fixed concentration approximating $50-80 \%$ occupancy at the target. However, tracers can be exploited to provide a more quantitative apparent affinity value, as engagement potency is often dependent on the concentration and affinity of the tracer used in the assay. As the tracer and test compound bind to the target in a competitive and mutually exclusive manner, the relationship between the apparent $\mathrm{IC}_{50}$ of the test compound and the concentration of tracer used in the assay is governed by the Cheng-Prusoff Equation [8] (Eq. 2).

$$
K_{\mathrm{i}, \text { app }}=\frac{\mathrm{IC}_{50}}{1+\left(\frac{\text { [tracer] }}{K_{\mathrm{d}, \text { app }}}\right)}
$$

Equation 2 provides the quantitative capability to extract an apparent dissociation constant $\left(K_{\mathrm{i}, \text { app }}\right)$ for the test compound. This analysis yields a value that is insensitive to tracer concentration. Considering the limits of Eq. 2 with respect to tracer concentration, in situations where the concentration of tracer is much less than its affinity $\left(K_{\mathrm{d} \text {,app }}\right)$, the measured $\mathrm{IC}_{50}$ for the test compound will generally be within twofold of the $K_{\mathrm{i}, \text { app }}$ (i.e., if [tracer] $<<K_{\mathrm{d}}$, app, then $\left.\mathrm{IC}_{50} \cong K_{\mathrm{i}, \text { app }}\right)$. Conversely, when the concentration of tracer increases above the $K_{\mathrm{d} \text {,app }}$, the apparent $\mathrm{IC}_{50}$ value of the test compound shifts to higher concentrations.

The Cheng-Prusoff relationship can be used to determine the $K_{\mathrm{i}, \text { app }}$ for a test compound in multiple ways. For example, if the apparent affinity of the tracer $\left(K_{\mathrm{d}, \text { app }}\right)$ has already been measured, Eq. 2 can be used to convert an $\mathrm{IC}_{50}$ value measured at a single, known concentration of tracer to the $K_{\mathrm{i} \text {,app }}$ for the test compound. Alternatively, Eq. 2 can be algebraically linearized (Eq. 3 ) and used experimentally to extract the $K_{\mathrm{i}, \mathrm{app}}$, a method known as linearized Cheng-Prusoff analysis [9]. In practice, the apparent $\mathrm{IC}_{50}$ value for the test compound is measured at multiple tracer concentrations, 
A

CECR2
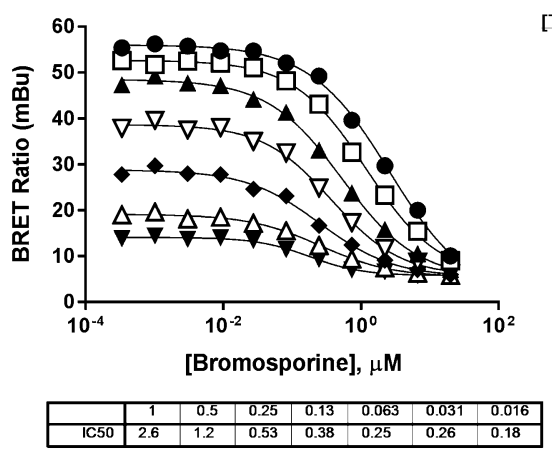

B

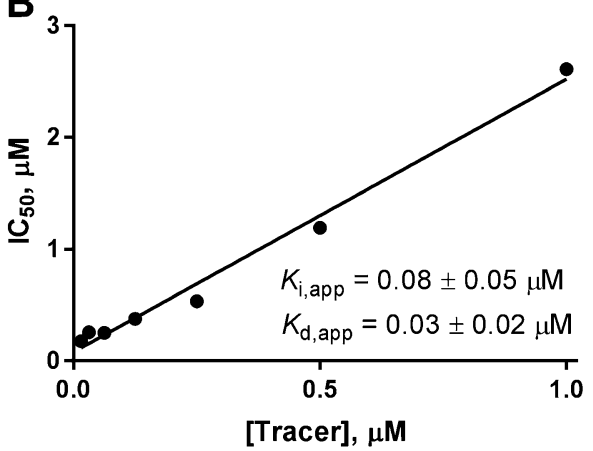

TAF1 (BD1-BD2)
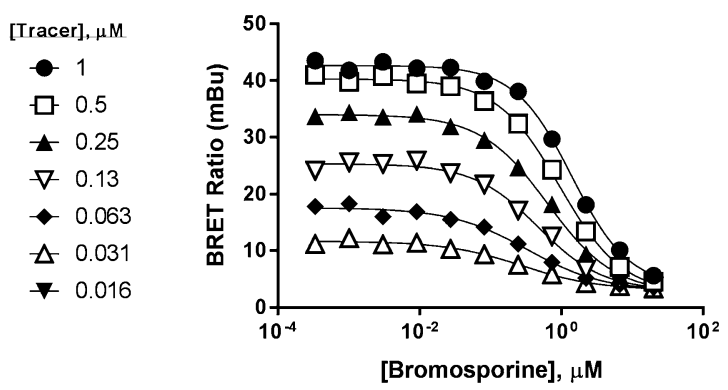

[Tracer], $\mu \mathrm{M}$

- 2

ㅁ. 1

$\pm 0.5$

$\nabla 0.25$

$\rightarrow 0.13$

$\Delta 0.063$

Fig. 7 Linearized Cheng-Prusoff analysis to determine bromosporine affinity to CECR2 Bromodomain (BD) and TAF1 BD1-BD2. HEK293 cells transiently expressing NanoLuc(R) fusions to bromodomains were seeded into 96-well plates and then treated with a dilution series of bromosporine at increasing concentrations of tracer. Panel A depicts dose-response curves for bromosporine at each individual tracer concentration. Individual curves were fitted with the sigmoidal dose-response curve to determine the apparent $\mathrm{IC}_{50}$. Replots of the $\mathrm{IC}_{50}$ values as a function of tracer concentration (panel B) show linearity and allowed calculation of the $K_{\mathrm{i}, \text { app }}$ for bromosporine and $K_{\mathrm{d}, \text { app }}$ of the tracer using Eq. 3

after which the $\mathrm{IC}_{50}$ values are replotted as a function of tracer concentration. Regression analysis yields a linear plot with a

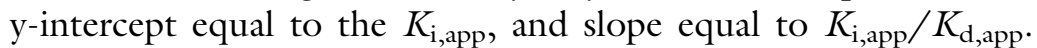
Figure 7 provides examples in which linearized Cheng-Prusoff analysis was used to quantify the $K_{\mathrm{i} \text {,app }}$ for the binding of the broad spectrum bromodomain inhibitor bromosporine to NanoLuc-bromodomain fusions.

$$
\mathrm{IC}_{50}=K_{\mathrm{i}, \mathrm{app}}\left(1+\frac{[\text { tracer }]}{K_{\mathrm{d}, \mathrm{app}}}\right)
$$

The linearized Cheng-Prusoff analysis is generally recommended for determinations of $K_{\mathrm{i} \text {,app }}$ for test compounds, particularly if binding of the tracer is saturable. For targets where tracer binding is weak and not saturable, but signal window (SW) is still 


\subsection{Liquid Handling Requirements and Considerations for High-Throughput Screening (HTS) and Lead Optimization}

adequate for $\mathrm{IC}_{50}$ determination (in practice, $\mathrm{SW} \geq 1.6$ ), the measured $\mathrm{IC}_{50}$ will often be a good approximation for the $K_{\mathrm{i} \text {,app }}$ (generally within twofold, as discussed above) (see Note 6).

Cellular target engagement assays can provide critical information for hit prioritization at both the HTS and lead optimization stages, particularly when the biochemical and cell-based assays fail to correlate. Accordingly, compounds that are similarly active in biochemical, cellular target engagement, and cellular activity assays can be assigned highest priority, while those that are very weak or inactive in a cellular target engagement assay, yet active in the other two formats, should be binned as suspicious. Such compounds are likely to trigger cellular activity assay inhibition through indirect effects. A sensitive cellular target engagement assay may also show correlative activity with the biochemical assay for certain compounds, yet fail to demonstrate cellular activity. In this case, the compound or compound series may be valid, yet require chemical optimization to allow cellular activity. It would therefore be valuable to apply the NanoBRET TM target engagement assay for HTS and as a key aid for dissection of mechanism in lead optimization.

It is possible to configure the steps and equipment to higher throughput, in order to enable efficient intracellular target engagement-based HTS and lead optimization. In order to afford the throughput required for HTS and lead optimization, several steps to streamline the NanoBRET ${ }^{\text {TM }}$ process are suggested. Strategies to maximize efficiency include switching from 96-well to 384-well format to reduce the number of plates required and the plate "real estate" occupied by controls, reducing the number of steps by using assay-ready plates, and implementation of robotic liquid handling protocols. Preparation of assay-ready plates requires acoustic droplet liquid dispensing technology. While relatively expensive, it is becoming increasingly available in core facilities within both academic and industrial research centers.

It is recommended that each 384 -well plate contain a set of controls occupying one entire row of 24 wells and comprising a dose response with a 12 -point concentration range. Be sure to include appropriate controls including a zero BRET control (i.e., no tracer) as well as a "BRET specificity control" (i.e., a high concentration of a control inhibitor in the presence of tracer) (see Notes 7 and 8 ).

Table 1 summarizes the results of target engagement analysis for a panel of full-length intracellular kinases in a scaled format (i.e., automated, 384-well format). As a measure of statistical robustness, each assay yielded a Z' above 0.4 , supporting suitability in HTS work flows. As a future direction, scaling the BRET technique to higher density (e.g., 1536-well plates) may be possible. 


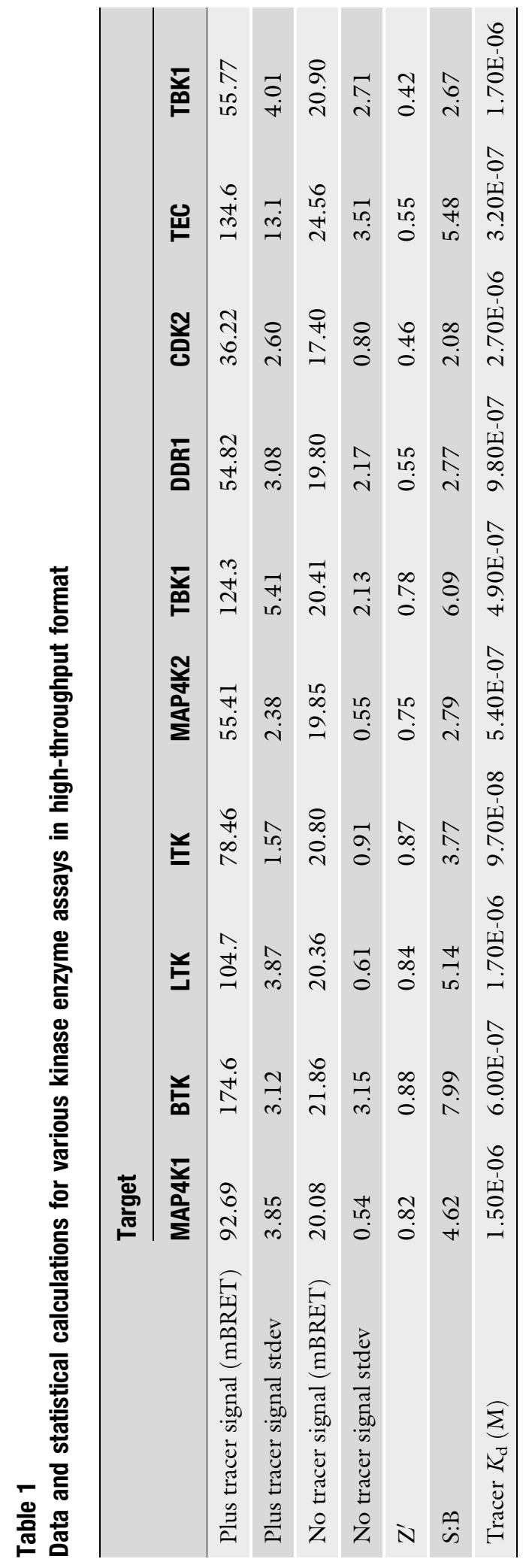


3.4.1 [Day 1]:

Predispense of Test

Compounds to Assay Plate

3.4.2 [Day 2]:

Preparation of Cells with

1× Tracer for BRET Assay

3.5 Optimization of Energy Transfer for Residence Time Studies in Live Cells
1. Aliquot test and control compound stocks in 100\% DMSO at high concentration (typically either 5 or $10 \mathrm{mM}$ depending on desired final assay concentration of 10 or $20 \mu \mathrm{M}$, respectively) to acoustic dispense qualified mother plates. Depending on equipment, one or more additional dilutions likely are required.

2. Adjust instrument to dispense $80 \mathrm{~nL}$ of highest concentration, then $1: 3$ dilutions using $100 \%$ DMSO as backfill in order to create a 12-point dilution series of $80 \mathrm{~nL}$ total volume in each well. Since the lowest dispense amount may be $5 \mathrm{~nL}$, several intermediate dilutions of the initial 5 or $10 \mathrm{mM}$ stock likely are required to achieve the required dispenses.

3. Seal plates tightly and store at $4{ }^{\circ} \mathrm{C}$ until day 2 of assay.

1. Harvest cells as described in Subheading 3.2.2 and adjust the cell density to $2 \times 10^{5} / \mathrm{mL}$ in Opti-MEM without serum or phenol red.

2. Dispense $38 \mu \mathrm{L}$ per well of cell suspension/extracellular NanoLuc Inhibitor into white, 384-well plate containing previously dispensed, serially diluted test and control compounds.

3. Prepare the BRET tracer at the lowest concentration determined to yield a useable signal:background and $Z$ ' greater than 0.5 , optimally $50-80 \%$ of full target occupancy.

4. Add $2 \mu \mathrm{L}$ of Complete $20 \times$ tracer per well to cells in suspension. Mix thoroughly using appropriate instrumentation.

5. Incubate plates in a humidified, $37{ }^{\circ} \mathrm{C} / 5 \% \mathrm{CO}_{2}$ incubator for $2 \mathrm{~h}$.

6. Add $20 \mu \mathrm{L}$ per well of $3 \times$ Complete NanoBRET(TM) Nano-Glo(R) Substrate for a 384-well plate. Incubate 2-3 min at room temperature prior to first read; readings are stable at least $60 \mathrm{~min}$.

7. Measure BRET as described in Subheading 3.2.4.

Although equilibrium-based analysis is predictive of engagement in a closed system (i.e., conditions of static drug concentrations), nonequilibrium analysis may better predict target occupancy in open systems, where drug concentrations are dynamic. The compound residence time (i.e., $k_{\text {off }}{ }^{-1}$ ) may better dictate target occupancy in the dynamic regime of a living organism $[10,11]$. The energy transfer technique can be readily configured to measure real-time binding kinetics in live cells, thus providing an approach to assess drug residence in an artificial open system. The open system can be simulated by applying an acute treatment of test compound to the cells, followed by removal of unbound compound and a real-time measurement of residence time using energy transfer (Fig. 8). 
1. Treat with test ligand at $10-20 \mathrm{X}$ of $K_{\mathrm{i}, \text { app }}$

2. Perform wash step

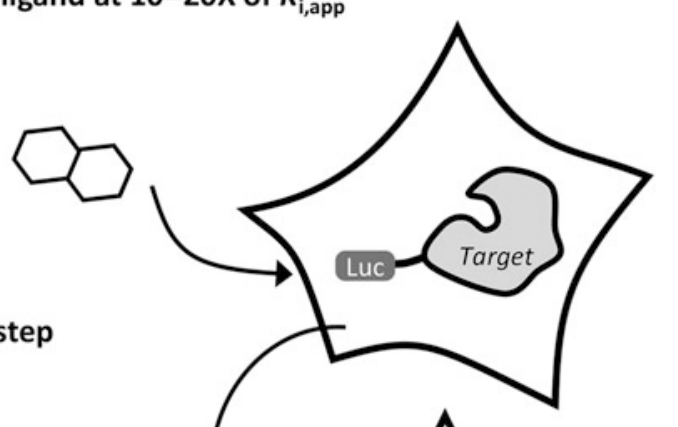

3. Add energy transfer probe

4. Immediately measure BRET

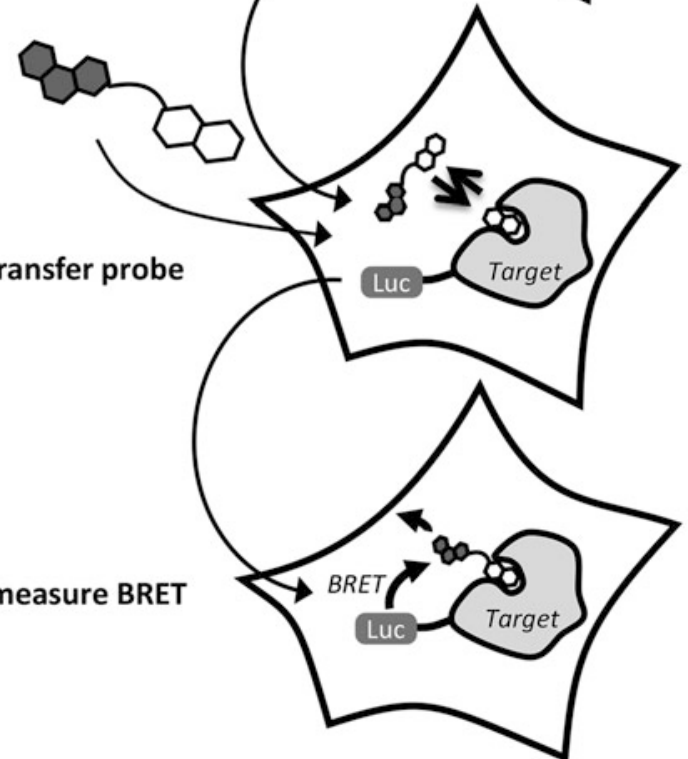

Optional: Permeabilize the cells to rule out rebinding

Fig. 8 Illustration of BRET for intracellular residence time analysis

Prior to performing a residence time analysis, it is important to determine a few key parameters. First, it is important to select an optimal tracer and determine a working concentration of the tracer for BRET measurement after compound washout. In general, it is recommended to use a saturating concentration of tracer that has fast association and dissociation kinetics with the target of interest. While this may be achievable in practice, the binding of the tracer might not be saturable for some targets. Thus, it is important to optimize the association kinetics at the highest tracer concentration possible. For new tracers and/or new target combinations, it is recommended to initially evaluate the kinetic parameters in a dose-responsive manner to ensure that an optimal tracer and working concentration are selected for the downstream residence time analysis. This is accomplished via observed rate constant $\left(k_{\text {obs }}\right)$ analysis, wherein the establishment of BRET at the target is measured kinetically over time at increasing tracer concentrations. 

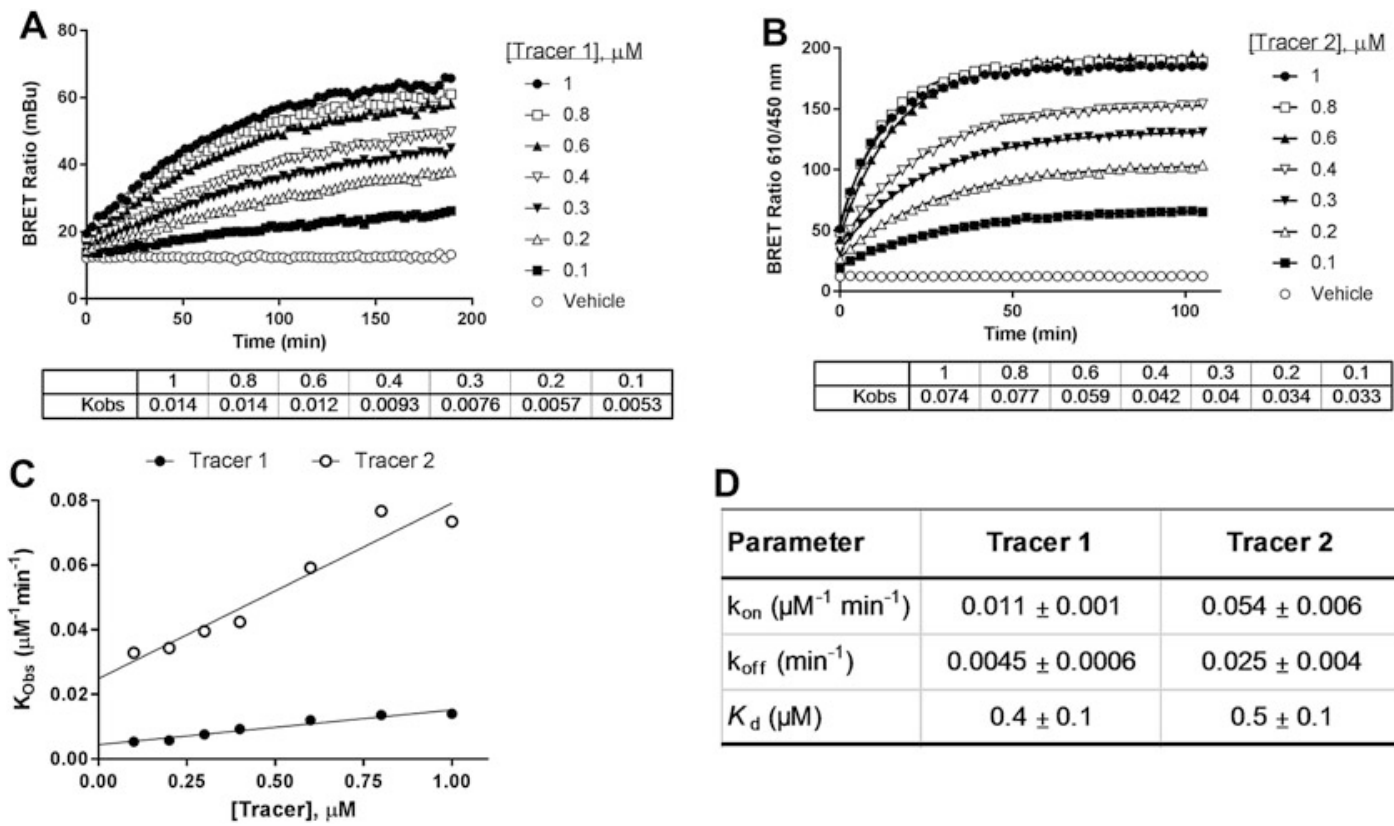

D

\begin{tabular}{|l|c|c|}
\hline Parameter & Tracer 1 & Tracer 2 \\
\hline $\mathrm{K}_{\text {on }}\left(\mu \mathrm{M}^{-1} \mathrm{~min}^{-1}\right)$ & $0.011 \pm 0.001$ & $0.054 \pm 0.006$ \\
\hline $\mathrm{K}_{\text {off }}\left(\mathrm{min}^{-1}\right)$ & $0.0045 \pm 0.0006$ & $0.025 \pm 0.004$ \\
\hline$K_{\mathrm{d}}(\mu \mathrm{M})$ & $0.4 \pm 0.1$ & $0.5 \pm 0.1$ \\
\hline
\end{tabular}

Fig. 9 Kinetic optimization of bromodomain tracers. HEK293 cells transiently expressing NanoLuc(R)-BRD9 bromodomain were seeded into 96-well plates, after which a dilution series of tracer was added and the BRET measured kinetically. Panels A and B depict tracer association curves for two different bromodomain tracers. Individual points represent the mean of three technical replicates. Nonlinear regression analysis using the one-phase association equation (Eq. 4) was performed to extract an observed rate constant $\left(\mathrm{k}_{\mathrm{obs}}\right)$ at each tracer concentration. Observed rate constants were replotted with respect to tracer concentration (panel C), yielding linear relationships. Kinetic parameters extracted by linear regression using Eq. 5 are tabulated in panel D. Tracer 2 gave faster association and dissociation kinetics compared to tracer 1 and was chosen for downstream residence time analyses at a working concentration of $1 \mu \mathrm{M}$

Subsequently, the $k_{\text {obs }}$ is determined by nonlinear regression analysis of the kinetic curves for each tracer concentration using the one-phase association equation (Eq. 4), assuming pseudo-first order association [12]. The $k_{\text {obs }}$ values are replotted with respect to tracer concentration, which yields a linear relationship. Fitting Eq. 5 to the data allows dissection of the $k_{\text {on }}$ (from the slope) and $k_{\text {off }}$ (from the $\mathrm{y}$-intercept) of the tracer. Figure 9 provides an example in which a $k_{\text {obs }}$ analysis is performed to choose between two different tracers for kinetic analysis of the BRD9 Bromodomain.

$$
\begin{gathered}
\Upsilon=\Upsilon_{\mathrm{o}}+\left(\text { Plateau }-\Upsilon_{\mathrm{o}}\right) \times\left(1-\mathrm{e}^{-k_{\mathrm{obs}} * t}\right) \\
k_{\mathrm{obs}}=k_{\mathrm{on}} \times[\text { tracer }]+k_{\mathrm{off}}
\end{gathered}
$$

Generally, higher values of both $k_{\text {on }}$ and $k_{\text {off }}$ are desired for residence time analysis to ensure that the tracer binding is at equilibrium with the target at any given time once the test compound dissociates. However, in many cases, a simple comparison of the 

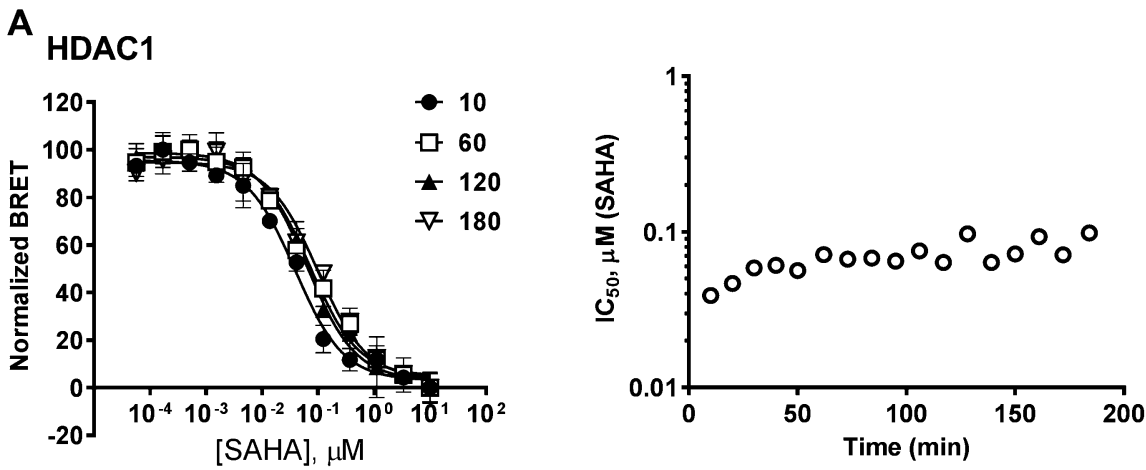

\section{B HDAC1}
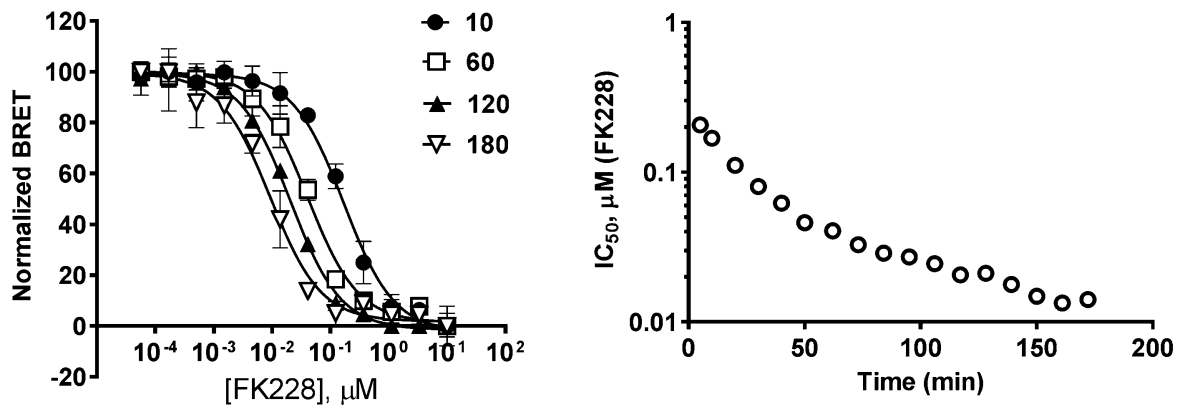

Fig. 10 Determination of optimal inhibitor concentrations for compound treatment prior to residence time analysis. BRET analysis was performed in real-time to determine an appropriate equilibration time and inhibitor concentration for cellular washout experiments. In general, an inhibitor concentration approximating $90 \%$ occupancy (e.g., $10-20 \times K_{\mathrm{i}, \text { app }}$ ) is optimal prior to washout studies. (a) For HDAC1, equilibration with SAHA was proven to be rapid, indicating that a concentration of $1 \mu \mathrm{M}$ SAHA is suitable following a short incubation time. (b) For FK228, equilibration kinetics were slower, indicating that a dose of $100 \mathrm{nM}$ is appropriate, and $3 \mathrm{~h}$ of equilibration is required to achieve HDAC1 occupancy

relative $k_{\text {obs }}$ value itself may be sufficient to select an optimal tracer among a few lead candidates. Though equilibration for tracers may vary greatly (nearly instantaneous to hours), equilibration of the tracer at the target within $20-30 \mathrm{~min}$ is sufficient for a qualitative assessment (i.e., rank-order assessment) of test compound residence time.

After the tracer and working concentrations are established, it is recommended to determine an appropriate acute dose of the test compound, as well as the length of time required to achieve equilibration with the target in the cellular context (see Note 9). Figure 10 provides an example for the determination of the acute dose and equilibration time for the binding of two test compounds to the histone deacetylase, HDACl. Figures 11 and 12 provide example residence time analyses for the binding of the same two test compounds at $\mathrm{HDACl}$, with cell permeabilization controls to evaluate the effect of intracellular trapping, respectively. 


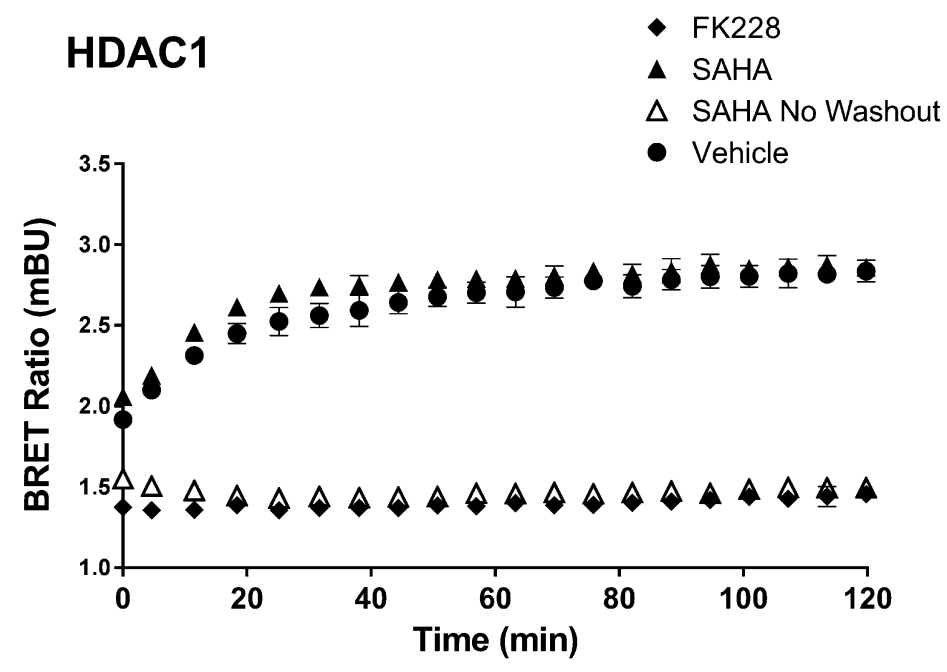

Fig. 11 Residence time analysis of HDAC1 with SAHA and FK228 in live cells. SAHA shows rapid dissociation, as expected. The occupancy of HDAC1 with FK228 following washout was equivalent to the full occupancy control (SAHA, no washout), thus indicating durable binding. Thus, FK228 shows protracted residence time at HDAC1, consistent with previous reports

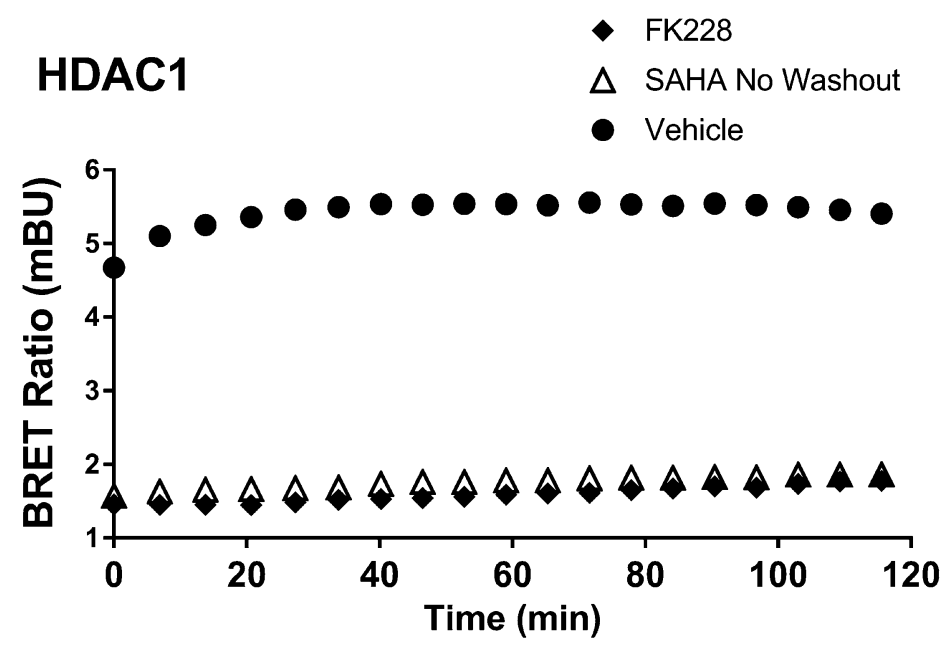

Fig. 12 Control residence time experiments in permeabilized cells to ensure that kinetic profiles are not influenced by intracellular trapping of the test compound. FK228 maintains a long residence time after permeabilization of the cells, thus supporting previous results in live cells of durable binding

3.5.1 Adding Test Compound to Cells
1. After transfecting cells (as described in Subheading 3.2.1), resuspend cells using prewarmed assay medium (e.g., OptiMEM without serum or phenol red).

2. Adjust the density to $2 \times 10^{5}$ cells $/ \mathrm{mL}$ in assay medium in a $15 \mathrm{~mL}$ sterile polypropylene conical tube. We recommend a minimum volume of $1 \mathrm{~mL}$ of cells, ideally $5 \mathrm{~mL}$ of cells. 
3.5.2 Preparing BRET Reagents

3.5.3 Preparing Cells and Dispensing Reagents for the Residence Time Assay
3. Prepare test compound at $10 \times$ final concentration in appropriate solvent (e.g., 1\% DMSO).

4. To determine the optimal concentration of test compound for residence time analysis, it is recommended to first determine the compound $\mathrm{IC}_{50}$ using the equilibrium-based Target Engagement Protocol (see Subheading 3.2.2). Introduce the test compound at a final concentration of 10-20 $\times K_{\mathrm{i}, \text { app }}$ determined under equilibrium conditions. This insures that adequate washout conditions can be achieved prior to off-rate measurements. Add $100 \mu \mathrm{L}$ of $10 \times$ test compound to each $1 \mathrm{~mL}$ of cells in assay medium and mix gently.

(Optional) Include a positive control treatment of a compound at a high and saturating dose as a full-occupancy control, as well as a negative control treatment with compound vehicle.

5. Place the conical tube in a rack, and incubate the tube with the cap loosened at $37^{\circ} \mathrm{C}, 5 \% \mathrm{CO}_{2}$ for a minimum of $2 \mathrm{~h}$ or until sample is expected to reach equilibrium.

1. To prepare Complete $20 \times$ tracer reagent, first prepare a $100 \times$ solution of BRET tracer in 100\% DMSO. Add 4 parts Tracer Dilution Buffer to 1 part of $100 \times$ tracer to generate Complete $20 \times$ tracer reagent.

2. For analysis of residence time in live cells, prepare a $2 \times$ solution of NanoBRET(TM) Nano-Glo(R) Substrate plus Extracellular NanoLuc Inhibitor by diluting the NanoBRET(TM) Nano-Glo (R) Substrate 1:250 and the Extracellular NanoLuc(R) Inhibitor 1:750 in a conical tube with Opti-MEM without serum or phenol red. For example, for a 96-well plate, mix $40 \mu \mathrm{L}$ of NanoBRET(TM) Nano-Glo(R) Substrate, $13.3 \mu \mathrm{L}$ of Extracellular NanoLuc(R) Inhibitor and $9946 \mu \mathrm{L}$ of assay medium to produce $10 \mathrm{~mL}$ of $2 \times$ NanoBRET TM Nano-Glo(R) Substrate plus Extracellular NanoLuc(R) Inhibitor Solution. Mix gently by inversion 5-10 times. For analysis of residence time in permeabilized cells, include $100 \mu \mathrm{g} / \mathrm{mL}$ digitonin and omit the Extracellular NanoLuc(R) inhibitor in the $2 \times$ solution.

1. After incubation with test compound is complete, centrifuge cells at $200 \times g$ for $5 \mathrm{~min}$.

2. Optional Wash: To remove unbound test compound, resuspend cells in prewarmed assay medium, centrifuge cells and remove medium. Maintain the concentration of the positive control compound for the full-occupancy control.

3 . Remove medium, resuspend cells in prewarmed assay medium, and adjust cell density to $2 \times 10^{5}$ cells $/ \mathrm{mL}$. 
3.5.4 BRET Detection in Kinetic Mode

3.5.5 Adapting the Residence Time Protocol to Adherent (ADH) Format
4. Dispense $90 \mu \mathrm{L}$ per well of cell suspension with test compound or controls into white, 96-well plates. Periodically mix cells to avoid cell settling in the tube.

(Optional) For background correction, dispense $100 \mu \mathrm{L}$ of cell suspension in triplicate as no-tracer control samples.

5. Add $100 \mu \mathrm{L}$ of $2 \times$ NanoBRET(TM) Nano-Glo(R) Substrate prepared above (see Subheading 3.5.2).

6. Dispense $10 \mu \mathrm{L}$ of Complete $20 \times$ NanoBRETTM Tracer Reagent per well to cells. Mix the 96-well plate on an orbital shaker for $15 \mathrm{~s}$ at $900 \mathrm{rpm}$.

(Optional) Prepare a separate set of samples without tracer for optional background correction steps.

7. Immediately proceed to the next step (see Subheading 3.5.4).

1. Set a NanoBRETTM Assay-compatible instrument to perform repeat measurements for the desired time interval. As a starting point, use 5-min intervals between each measurement, and be sure to include a sufficient number of measurements to determine compound dissociation. Set the instrument at $25^{\circ} \mathrm{C}$ to minimize sample evaporation. However, as temperature may impact residence time profiles, it may be valuable to evaluate physiological temperatures.

2. Measure donor emission wavelength (e.g., $450 \mathrm{~nm}$ ) and acceptor emission wavelength (e.g., $600 \mathrm{~nm}$ ), and determine the BRET ratio as described earlier (see Subheading 3.2.4).

In addition to the residence time protocol described above, residence time analysis can be performed in adherent $(\mathrm{ADH})$ format in which the cells are adhered to a tissue culture-treated assay plate and the compound incubations are performed directly in that assay plate. Adherent format has both benefits and drawbacks compared to the conventional format in the nonbinding surface assay plate (NBS format) described above that include the ability to test significantly more experimental conditions simultaneously (test compound concentrations and/or targets), and improved workflow for washout that reduces time between the initial washout and the tracer addition step and preserves kinetic information at early time points. However, in some cases the kinetics of the BRET signal may not achieve a constant value under steady state conditions, or may appear biphasic compared to those assessed in NBS-treated plates.

Users should consider their specific goals for the residence time analysis to help select between the assay formats. Figure 13 depicts an example residence time determination for dasatinib and ibrutinib at BTK kinase in both NBS and $\mathrm{ADH}$ formats for comparison. 

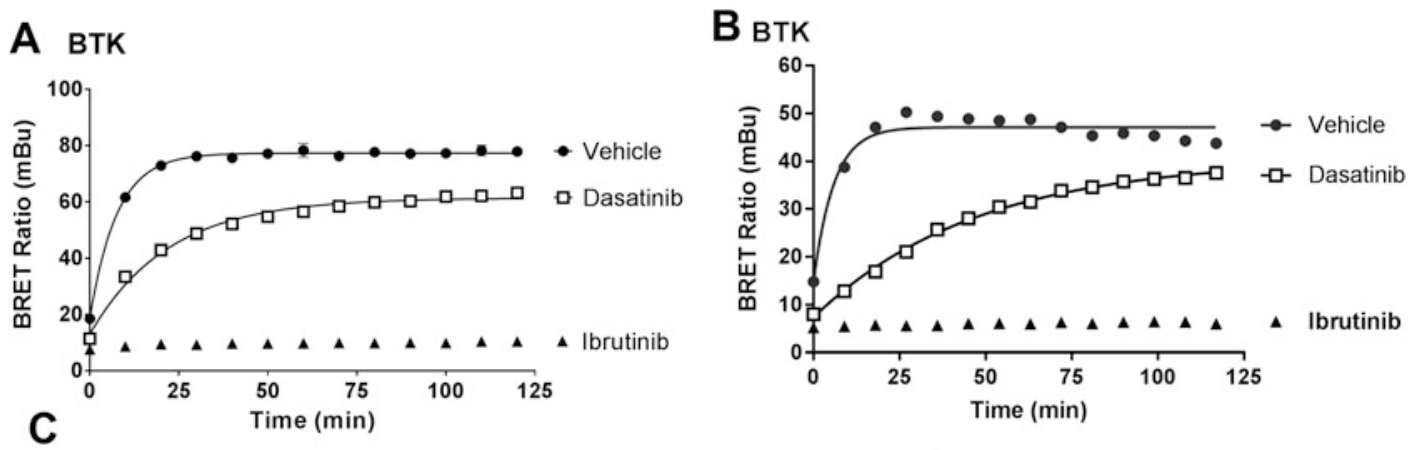

\begin{tabular}{l|c|c|}
\hline Compound & NBS $\mathbf{~}_{\text {obs }}\left(\mathbf{m i n}^{-1}\right)$ & Adherent $\mathbf{k}_{\text {obs }}\left(\mathbf{m i n}^{-1}\right)$ \\
\hline Vehicle & $0.13 \pm 0.01$ & $0.17 \pm 0.04$ \\
\hline Dasatinib & $0.045 \pm 0.002$ & $0.021 \pm 0.002$ \\
\hline
\end{tabular}

Fig. 13 Comparison of residence time analysis in NBS vs adherent (ADH) formats. HEK293 cells expressing BTK-NanoLuc(R) kinase fusion were treated with DMSO vehicle, $250 \mathrm{nM}$ dasatinib, or $1 \mu \mathrm{M}$ ibrutinib for $2 \mathrm{~h}$. The cells were washed with Opti-MEM to remove unbound drug, after which $1 \mu \mathrm{M}$ kinase tracer 4 was added and NanoBRETTM measurements were recorded in kinetic mode. For kinase tracer 4, qualitative residence time analysis for dasatinib and ibrutinib revealed comparable apparent dissociation rates in both NBS format (panel a) and ADH format (panel b). In both formats, dasatinib showed protracted residence time at BTK, while ibrutinib completely prevents tracer association due to covalent binding. Observed rate constants $\left(k_{\mathrm{obs}}\right)$ for tracer association after washout of vehicle or dasatinib are tabulated in panel $\mathrm{C}$ for comparison

1. Mix desired cells with lipid-DNA complexes as described in Subheading 3.2.1.

2. Dispense $100 \mu \mathrm{L}$ cells and the lipid-DNA complex into a sterile, tissue-culture treated 96-well plate, and incubate at least $20 \mathrm{~h}$ to allow expression. We recommend a cell density of approximately $55,000-80,000$ cells $/ \mathrm{cm}^{2}$ during the transfection (for example, use approximately 20,000 cells/well for a 96-well Corning \#3917 assay plate).

3 . On day 2 , gently remove medium from the assay plate with transfected HEK293 cells via aspiration.

4. Add back $90 \mu \mathrm{L}$ per well of prewarmed assay medium. Include suitable controls as indicated in Subheadings 3.5.1 and 3.5.3.

5. Add $10 \mu \mathrm{L}$ of $10 \times$ test compound to each assay well. For fulloccupancy control, include a sample with a saturating dose of a positive control compound. For zero-occupancy control, add only DMSO. If the optional "No tracer control samples" were added to the experiment, do not add test compound.

6. Mix on orbital shaker for $15 \mathrm{~s}$ at $900 \mathrm{rpm}$.

7. Incubate the assay plate at $37^{\circ} \mathrm{C}, 5 \% \mathrm{CO}_{2}$ for a minimum of $2 \mathrm{~h}$ or until sample is expected to reach equilibrium. Shorter or longer incubation times may be required depending on the characteristic of the test compound. 
8. After incubation with test compound is complete, gently aspirate to remove the medium and test compound from the assay plate. For the full-occupancy control, do not perform this step. Test compound should remain in the sample.

9. To remove residual unbound test compound, gently add $150 \mu \mathrm{L}$ of assay medium to each well and incubate at room temperature for $30 \mathrm{~s}$. For the full-occupancy control, do not perform this step. Test compound should remain in the sample.

10. Gently aspirate the medium and dispense $90 \mu \mathrm{L}$ per well of assay medium.

11. Add $100 \mu \mathrm{L}$ of $2 \times$ NanoBRET(TM) Nano-Glo(R) Substrate plus Extracellular NanoLuc(R) Inhibitor solution to each well of the 96-well plate (prepared as described in Subheading 3.5.2 in the protocol for residence time in NBS format).

12. Dispense $10 \mu \mathrm{L}$ of Complete $20 \times$ NanoBRET(TM) Tracer Reagent per well. Mix the 96-well plate on an orbital shaker for $15 \mathrm{~s}$ at $900 \mathrm{rpm}$.

13. Immediately measure BRET in kinetic mode as described in Subheading 3.5.4 in the protocol for residence time in NBS format.

14. Process data as described above in the protocol for residence time in NBS format (see Subheading 3.5.4).

1. Progress of the reaction can be monitored by analyzing a small aliquot every $15 \mathrm{~min}$. Additional time may be required to achieve satisfactory results. Slow reaction can often be remedied by adding an additional $8.6 \mu \mathrm{L}$ portion of diisopropylethyl amine. Overnight reaction is not recommended.

2. It is recommended that fraction pools be concentrated to dryness under reduced pressure. Coevaporation with acetonitrile will help remove spurious residual TFA that has been shown to affect the stability of some tracers. Lyophilization has been shown to enhance this effect during freeze-drying and is not recommended.

3. When possible, placement of the luciferase reporter at both termini of the target protein is recommended to identify the optimal donor orientation. Installation of a 4-10 residue linker between the target and luciferase reporter is also recommended. Standardized poly Gly/Ser linkers (e.g., Gly-Ser-SerGly) are commonly used to ensure some level of flexibility between the target and the reporter. Although a variety of vectors can be configured for such purposes, common mammalian expression vectors such as $\mathrm{pFN}-31 \mathrm{~K}$ or $\mathrm{pFC}-32 \mathrm{~K}$ are predesigned for NanoBRET(TM). 
4. It is recommended that the maximum concentration of tracer used at this stage is $0.4 \mathrm{mM}$ so that the maximum concentration on cells does not exceed $4 \mu \mathrm{M}$. This is typically the solubility limit of cell-permeable NanoBRET(TM) tracers, so higher concentrations in culture medium should be avoided.

5. The Extracellular $\operatorname{NanoLuc}(\mathrm{R})$ inhibitor is recommended for live cell analysis as a means to inhibit any Nluc signal arising from targets in cell culture debris. For experiments with cell lysates, it should be omitted.

6. When planning the linearized Cheng-Prusoff analysis, it is important to consider the concentration range of both tracer and the test compound. Ideally, both will be used at or below the associated solubility threshold. When these thresholds are surpassed, deviations in linearity in the regression analysis are commonly observed, thus complicating quantitative analysis with NanoBRET(TM). When choosing tracer concentrations, it is ideal to include concentrations both above and below the $K_{\mathrm{d} \text {,app }}$, typically in the range of $0.25-20 \times K_{\mathrm{d} \text {,app }}$. This ensures adequate competition and establishment of the linear rightshifting of test compound $\mathrm{IC}_{50}$. As the analysis requires linear regression, linear spacing of the tracer concentration is ideal, although not always practical. Hence, a twofold dilution series of the tracer is often used to bracket the $K_{\mathrm{d} \text {,app }}$. In the case of the test compound, generally an 11-point, threefold dilution series is most appropriate for capturing the $\mathrm{IC}_{50}$ values, often starting at $50 \times$ the apparent $\mathrm{IC}_{50}$ at a particular tracer concentration, or $1000-2000 \times$ the $K_{\mathrm{i} \text {,app }}$ of the test compound for a full analysis. In situations where a new test compound/tracer combination is being evaluated, it is often practical to perform a pilot analysis with a twofold dilution series of tracer starting in the range of $1-4 \mu \mathrm{M}$ and a threefold dilution series of the test compound starting in the range of $10-20 \mu \mathrm{M}$, after which the concentration ranges can be adjusted as needed.

7. When test compounds are applied to the plate in 12-point concentration dilution, as many as $30 \mathrm{IC}_{50}$ curves can be determined on a single 384-well plate. If duplicate dose-response curves are determined on a single plate and a duplicate control compound dilution series also is run on every plate for interplate and interday statistical comparisons, then a reasonable throughput of 14 compounds per plate can be achieved. The NanoBRETTM signal is stable for at least $60 \mathrm{~min}$; therefore at least 15-20 plates can be filled and scanned efficiently using appropriate bulk dispensing equipment without loss of signal between reading the first and last plates.

8. Adapting the competitive displacement format to high throughput requires additional tactics to assure consistency plate-to-plate and day-to-day. These include normalizing the 
amount of DMSO in every well and freezing many vials of cells at the same passage number. The robustness of this format should be assessed by repeating tracer dose response and dose response for a selected control test compound on multiple plates, on different days, with different transient transfections, and using cells with different passage numbers or different vials of frozen cells. Test-retest Minimum Significant Ratio (MSR) and moving MSR values should be within threefold in each repeat assay [13]. As is typical for assay development and daily evaluation, assay behavior also should be evaluated using $Z$ values. With appropriate assay development, the highthroughput format behaves essentially identical to the 96-well standard format. Tracer dose response $K_{\mathrm{d} \text {,app}}$, signal-background ratio, and $Z$ values have been found to be comparable between 96- and 384-well plate formats for multiple different kinase NanoBRET(TM) assays studied, for example. Table 1 illustrates data for ten archetypal enzymes across multiple kinase classes. In each case, the 384-well assay was developed, and the statistical effect size (measured as $Z$ ) is acceptable for HTS and lead optimization. There is no need to first develop and optimize an assay in 96-well format prior to adapting 384-well format.

9. The acute dose can be determined by measuring the $K_{\mathrm{i} \text {,app }}$ or $\mathrm{IC}_{50}$ of the test drug according to the protocols described above in Subheadings 2 and 3. Once determined, we recommend an acute dose of $10-20 \times K_{\mathrm{i}, \text { app }}$ or $\mathrm{IC}_{50}$ for the residence time analysis, which balances both meaningful binding of the test compound to the target of interest (approximately 90\% occupancy) as well as the ability to wash away the compound after equilibration. To determine an appropriate equilibration time, it is recommended to monitor the affinity of the test compound to the target over time, and select a sufficient amount of time for stabilization of the $\mathrm{IC}_{50}$ value (indicative of equilibration). The binding of many test compounds will reach equilibrium with the target within $2-3 \mathrm{~h}$ in a cellular context, although the incubation time might require adjustment for poorly permeable compounds.

\section{References}

1. Savitski MM, Reinhard FB, Franken H, Werner T, Savitski MF, Eberhard D, Martinez Molina D, Jafari R, Dovega RB, Klaeger S, Kuster B, Nordlund P, Bantscheff M, Drewes G (2014) Proteomics. Tracking cancer drugs in living cells by thermal profiling of the proteome. Science 346(6205):1255784. https:// doi.org/10.1126/science.1255784

2. Bantscheff M, Hopf C, Savitski MM, Dittmann A, Grandi P, Michon AM,
Schlegl J, Abraham Y, Becher I, Bergamini G, Boesche $M$, Delling $M$, Dumpelfeld $B$, Eberhard D, Huthmacher C, Mathieson T, Poeckel D, Reader V, Strunk K, Sweetman G, Kruse U, Neubauer G, Ramsden NG, Drewes G (2011) Chemoproteomics profiling of HDAC inhibitors reveals selective targeting of HDAC complexes. Nat Biotechnol 29 (3):255-265. https://doi.org/10.1038/nbt. 1759 
3. Robers MB, Dart ML, Woodroofe CC, Zimprich CA, Kirkland TA, Machleidt T, Kupcho KR, Levin S, Hartnett JR, Zimmerman K, Niles AL, Ohana RF, Daniels DL, Slater M, Wood MG, Cong M, Cheng YQ, Wood KV (2015) Target engagement and drug residence time can be observed in living cells with BRET. Nat Commun 6:10091. https://doi.org/10. 1038/ncomms10091

4. Vasta JD, Corona CR, Wilkinson J, Zimprich CA, Hartnett JR, Ingold MR, Zimmerman K, Machleidt T, Kirkland TA, Huwiler KG, Ohana RF, Slater M, Otto P, Cong M, Wells CI, Berger BT, Hanke T, Glas C, Ding K, Drewry DH, Huber KVM, Willson TM, Knapp S, Müller S, Meisenheimer PL, Fan F, Wood KV, Robers MB (2018) Quantitative, wide-spectrum kinase profiling in live cells for assessing the effect of cellular ATP on target engagement. Cell Chem Biol 25(2):206-214.ell. doi: https://doi.org/10.1016/j.chembiol.2017. 10.010

5. Forster M, Chaikuad A, Bauer SM, Holstein J, Robers MB, Corona CR, Gehringer M, Pfaffenrot E, Ghoreschi K, Knapp S, Laufer SA (2016) Selective JAK3 inhibitors with a covalent reversible binding mode targeting a new induced fit binding pocket. Cell Chem Biol 23(11):1335-1340. https://doi.org/10. 1016/j.chembiol.2016.10.008

6. Stoddart LA, Johnstone EK, Wheal AJ, Goulding J, Robers MB, Machleidt T, Wood KV, Hill SJ, Pfleger KD (2015) Application of BRET to monitor ligand binding to GPCRs. Nat Methods 12(7):661-663. https://doi. org/10.1038/nmeth.3398

7. Waring MJ, Chen H, Rabow AA, Walker G, Bobby R, Boiko S, Bradbury RH, Callis R, Clark E, Dale I, Daniels DL, Dulak A, Flavell L, Holdgate G, Jowitt TA, Kikhney A, McAlister M, Mendez J, Ogg D, Patel J,
Petteruti P, Robb GR, Robers MB, Saif S, Stratton N, Svergun DI, Wang W, Whittaker D, Wilson DM, Yao Y (2016) Potent and selective bivalent inhibitors of BET bromodomains. Nat Chem Biol 12 (12):1097-1104. https://doi.org/10.1038/ nchembio. 2210

8. Cheng Y, Prusoff WH (1973) Relationship between the inhibition constant $(\mathrm{Kl})$ and the concentration of inhibitor which causes 50 per cent inhibition (I50) of an enzymatic reaction. Biochem Pharmacol 22(23):3099-3108

9. Newton P, Harrison P, Clulow S (2008) A novel method for determination of the affinity of protein: protein interactions in homogeneous assays. $J$ Biomol Screen 13 (7):674-682. https://doi.org/10.1177/ 1087057108321086

10. Lu H, Tonge PJ (2010) Drug-target residence time: critical information for lead optimization. Curr Opin Chem Biol 14(4):467-474. https:// doi.org/10.1016/j.cbpa.2010.06.176

11. Copeland RA, Pompliano DL, Meek TD (2006) Drug-target residence time and its implications for lead optimization. Nat Rev Drug Discov 5(9):730-739. https://doi.org/ $10.1038 / \mathrm{nrd} 2082$

12. Edwards PR, Gill A, Pollard-Knight DV, Hoare M, Buckle PE, Lowe PA, Leatherbarrow RJ (1995) Kinetics of protein-protein interactions at the surface of an optical biosensor. Anal Biochem 231(1):210-217

13. Haas JV, Eastwood BJ, Sittampalam GS, Devanaryan V, Iversen PW, Weidner JR (2004) Minimum significant ratio-a statistic to assess assay variability. In: Sittampalam GS, Coussens NP, Brimacombe K et al (eds) Assay guidance manual. Eli Lilly \& Company and the National Center for Advancing Translational Sciences, Bethesda (MD)

Open Access This chapter is licensed under the terms of the Creative Commons Attribution 4.0 International License (http://creativecommons.org/licenses/by/4.0/), which permits use, sharing, adaptation, distribution and reproduction in any medium or format, as long as you give appropriate credit to the original author(s) and the source, provide a link to the Creative Commons license and indicate if changes were made.

The images or other third party material in this chapter are included in the chapter's Creative Commons license, unless indicated otherwise in a credit line to the material. If material is not included in the chapter's Creative Commons license and your intended use is not permitted by statutory regulation or exceeds the permitted use, you will need to obtain permission directly from the copyright holder. 